\title{
Hot mantle rising
}

The long-term cooling of Earth's mantle is recorded in the declining temperature and volume of its volcanic outpourings over time. However, analyses of 89-million-year-old lavas from Costa Rica suggest that extremely hot mantle still lurks below.

\section{Oliver Shorttle}

E arth's history has been punctuated by vast magmatic episodes. These events are preserved in the geological record as large igneous provinces - areas of Earth's surface flooded by millions of cubic kilometres of lava that erupted in short periods of time ${ }^{1}$. Thought to be triggered by upwelling plumes of hot mantle ${ }^{2}$, the size and frequency of these volcanic episodes may have been greater in the past, fuelled by the hotter mantle of Earth's Archaean eon ${ }^{3}$. During this time, a distinctive type of igneous rock - komatiite - formed from magmas with high eruption temperatures that cooled to grow long needle-like olivine crystals $^{4,5}$ (Fig. 1). The rarity of komatiite eruptions more recently in Earth's history ${ }^{4}$ is taken as evidence of the mantle's slow cooling ${ }^{3,6}$. However, komatiitic lavas that formed 89 million years ago from the volcanic outpourings of the nascent Galápagos plume have been found in the Tortugal suite of the Caribbean large igneous province ${ }^{7}$. Writing in Nature Geoscience, Trela et al. ${ }^{8}$ demonstrate that these lavas formed from anomalously hot mantle with a temperature similar to that which produced the ancient Archaean komatiites, challenging our view of Earth's thermal structure and history.

Understanding the thermal evolution of Earth is a foundational goal of the geological sciences that impacts all areas of the subject, from models of oil maturation in rift basins to early estimates of the planet's age. Indeed, during the nineteenth century it was Kelvin's calculations based on observations of surface heat flow that pointed towards an (erroneously) young age for Earth, challenging prevailing geological thought at that time $e^{9}$. It was only with the realization that the planet's vast silicate interior is convecting and contains sources of heat that the heat flux estimates were reconciled with the geological record, confirming Earth's antiquity.

The modern view is one of the planet as a giant thermal engine, redistributing the old primordial heat from accretion and the new heat from radioactive decay and inner-core crystallization throughout Earth and

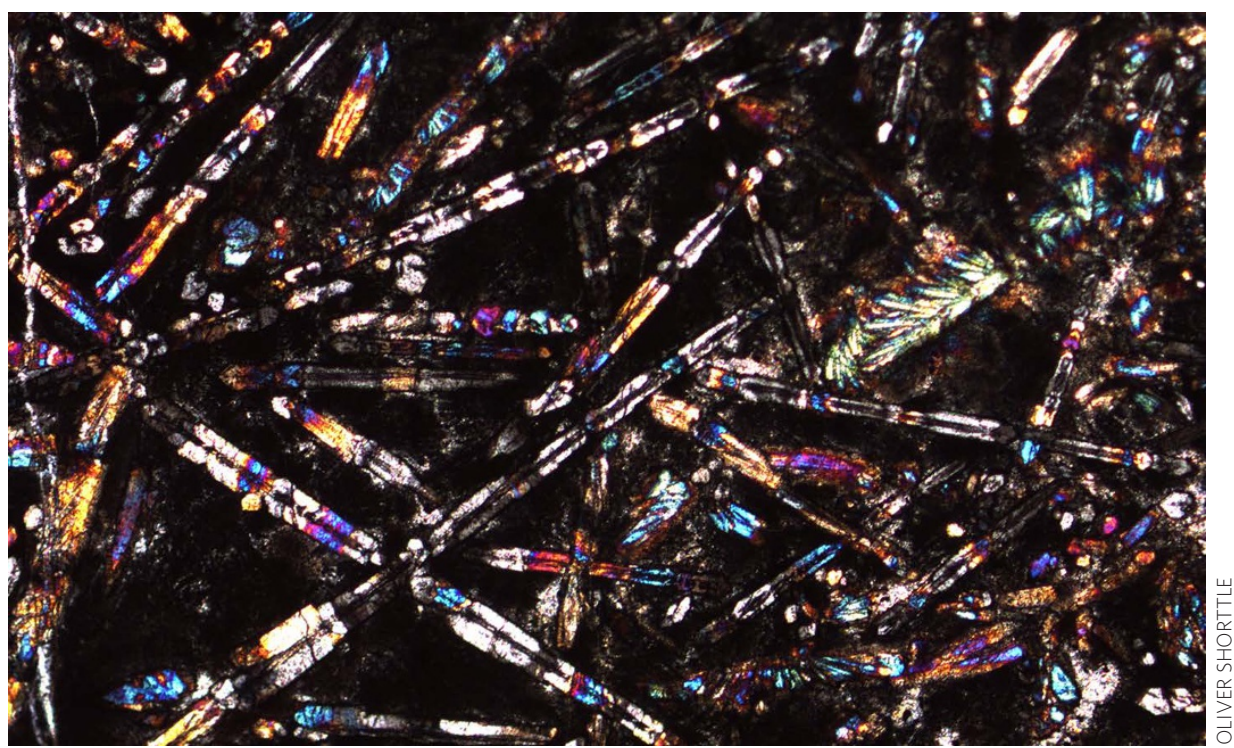

Figure 1 | A cross-polarized light image of the 2.7-billion-year-old Belingwe komatiite from Zimbabwe. Needle-like crystals of olivine give komatiites their characteristic texture ${ }^{5}$. Komatiites form from magmas with temperatures greater than $1,500{ }^{\circ} \mathrm{C}$ and were abundant during the Archaean, more than 2.5 billion years ago. As Earth's mantle cooled over time, fewer komatiites formed ${ }^{3}$. Trela and colleagues identify lavas erupted just 89 million years ago from a mantle source with similarly high temperatures to those that formed Archaean komatiites, implying that hot mantle domains are still present in the deep Earth. Field of view is $3 \mathrm{~mm}$ in width. Specimen courtesy of Mike Bickle.

ultimately to space ${ }^{6}$. This planetary cooling drives plate tectonics and the geodynamo phenomena that are probably critical for providing the clement conditions in which life may emerge and thrive.

Our present picture of Earth's thermal structure is anchored by observations from different depths within the planet. The chemistry and temperature of primitive erupted lavas can be used to reconstruct the temperature of the upper mantle, whereas seismic observations of temperaturedependent mineral phase changes can be used to infer temperatures at the base of the upper mantle. By taking into account the influence of pressure on temperature, these estimates can then be extrapolated to infer temperatures at greater depths, down to the core-mantle boundary. Applying this normalization to the temperature estimates made at various mantle depths, and accounting for phase changes, leads to a coherent picture in which ambient mantle potential temperature is approximately $1,300{ }^{\circ} \mathrm{C}$ (refs 10,11 ). Present-day variations about this typical upper-mantle temperature are of the order $200^{\circ} \mathrm{C}$ (refs 12,13).

Trela and colleagues ${ }^{8}$ use geochemical measurements of primitive lavas erupted above the early Galápagos plume and now preserved in Costa Rica - to reconstruct mantle temperatures. They find that the lavas formed from a mantle source that was $200{ }^{\circ} \mathrm{C}$ warmer than the hottest regions of the present-day mantle and $400{ }^{\circ} \mathrm{C}$ above its ambient temperature ${ }^{10}$. It is in the context of these present-day mantle temperatures that the observations from the Tortugal suite are remarkable. These lavas formed just 89 million years ago and are extremely young with respect to the major period of komatiite eruptions, 
2.5 billion years ago during the Archaean ${ }^{4}$. The existence of such hot eruptions implies that mantle domains with Archaeanlike temperatures are still formed or preserved in the deep Earth. Such longterm preservation of hot mantle domains resonates with a recent idea that lower mantle temperatures have long been close to the steady state, in contrast to the model of progressive mantle cooling that was previously assumed ${ }^{11}$.

To fully understand the significance of the unusually hot lavas from the Tortugal suite, it will be critical to place these high temperatures within the context of a self-consistent dynamical model for Earth's mantle. The intrinsic buoyancy of hot mantle and the speed of thermal diffusion suggest it would be difficult to preserve discrete domains of excess heat in the mantle in the same way, for example, that primordial chemical signatures might survive billions of years of convective stirring ${ }^{14}$. An alternate explanation could be that the young Galápagos plume dredged material from the thermal boundary layer at the core-mantle boundary, where temperatures probably rise by more than $1,000{ }^{\circ} \mathrm{C}$ over just a few hundred kilometres ${ }^{11}$. Future studies could test this hypothesis by searching for the subtle signatures of core-mantle interaction in the Tortugal komatiites ${ }^{15}$. If confirmed, this model would link processes occurring at 2,800 km depth in the Earth to the environmentally catastrophic formation of large igneous provinces at its surface.

Trela et al. ${ }^{8}$ characterize hot komatiitic lavas that erupted relatively recently, in geological terms, above the early Galápagos plume. The existence of such hot and relatively young lavas implies that regions of Earth's mantle with extreme temperatures are still present, and that this heat can be preserved in ascending mantle plumes and drive melting and volcanism at the present-day.
Oliver Shorttle is in the Department of Earth Sciences, The University of Cambridge, Cambridge CB3 OHA, UK.

e-mail:os258@esc.cam.ac.uk

References

1. Schoene, B. et al. Science 347, 182-184 (2015).

2. Campbell, I. H. Chem. Geol. 241, 153-176 (2007)

3. Herzberg, C., Condie, K. \& Korenaga, J. Earth Planet. Sci. Lett. 292, 79-88 (2010).

4. Arndt, N. \& Lesher, M. Komatiite (Cambridge Univ. Press, 2008).

5. Faure, F., Arndt, N. \& Libourel, G. J. Petrol. 47, 1591-1610 (2006)

6. Jaupart, C., Labrosse, S., Lucazeau, F. \& Mareschal, J.-C. in Treatise on Geophysics 2nd edn, Vol. 7 (ed. Schubert, G.) 223-270 (Elsevier, 2014).

7. Alvarado, G. E., Denyer, P. \& Sinton, C. W. Geology 25, 439-442 (1997).

8. Trela, J. et al. Nat. Geosci. 10, 451-456 (2017).

9. England, P., Molnar, P. \& Richter, F. GSA Today 17, 4-9 (2007).

10. Matthews, S., Shorttle, O. \& Maclennan, J. Geochem. Geophys. Geosyst. 17, 4725-4752 (2016).

11. Andrault, D. et al. Earth Planet. Sci. Lett. 443, 195-203 (2016).

12. Mckenzie, D. \& Bickle, M. J. J. Petrol. 29, 625-679 (1988).

13. Herzberg, C. \& Asimow, P. D. Geochem. Geophys. Geosyst. 16, 563-578 (2015)

14. Mukhopadhyay, S. Nature 486, 101-104 (2012).

15. Mundl, A. et al. Science 356, 66-69 (2017).

Published online: 22 May 2017 